\title{
CONTROL OF EPILACHNA VIGINTIOCTOPUNTATA FAB. (COLEOPTERA: COCCINELLIDAE) USING SOME INDIGENOUS PLANT EXTRACTS
}

\author{
Kamrul Islam¹, M. Saiful Islam²* and Zennat Ferdousi
}

Department of Genetic Engineering and Biotechnology, University of Rajshahi, Rajshahi 6205, Bangladesh;

${ }^{1}$ Present address: Department of Genetic Engineering and Biotechnology, Shahjalal University of Science and Technology, Sylhet 3114, Bangladesh; ${ }^{2}$ Department of Zoology, University of Rajshahi, Rajshahi

6205, Bangladesh *Corresponding author (email: saifulzoo@yahoo.co.uk)

\begin{abstract}
Epilachna vigintioctopunctata is an important pest that causes considerable economic losses to many crops including egg-plants. The crude aqueous extracts of leaves from three indigenous plants namely Ricinus communis, Calotropis procera and Datura metel were used against this beetle aiming at its control under laboratory conditions. Larvicidal bioassays of the extracts showed the following order of toxicity: $R$. communis $\left(\mathrm{LC}_{50}=18.40 \%\right)>$ C. procera $\left(\mathrm{LC}_{50}=23.70 \%\right)>$ D. metel $\left(\mathrm{LC}_{50}=29.61 \%\right)$. Subsequent data on some vital life-history traits were promising because the extracts significantly reduced both oviposition and egg-hatch, prolonged larval duration $(\mathrm{P}<0.001)$, and inhibited pupae formation and adult emergence $(\mathrm{P}<0.05)$. However, female ratio was not significantly affected by the treatments. Relevance of these findings on the control of this phytophagous species has been discussed.
\end{abstract}

Key words: Epilachna, life-history traits, indigenous plants, aqueous extract, phytochemicals.

muं rsk: Epilachna vigintioctopunctata $n \neq " \mathrm{Q}$ 把, b MQmn A _

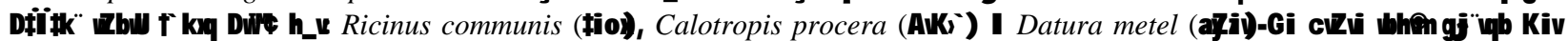

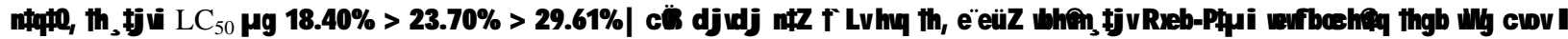

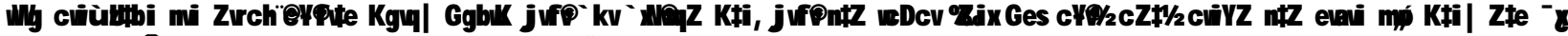

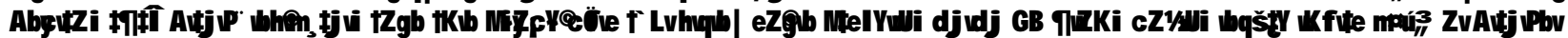

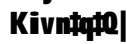

\section{Introduction}

Indiscriminate use of pesticides for insect pest management results in various environmental and ecological problems such as pest resistance and outbreak of secondary pests (Hagen and Franz 1973), long persistence, bioaccumulation and health hazards (Bhaduri et al. 1989) and environmental pollution (Devi et al. 1986; Fishwick 1988). Substitutes are being strongly conceived whereby researchers are now paying much emphasis on the biologically active indigenous plant products because they are environmentally safe, biodegradable and cost effective (Saxena et al. 1983; Ghani 1998). Plant extracts contain botanical insecticides or phytochemicals that could be used to repel, deter feeding, or limit reproduction and survival of various insect pest species including coccinellid ladybird beetles (Rajagopal and Trivedi 1989; Mondal and Ghatak, 2007; Ghatak and Mondal 2008; Swaminathan et al. 2010).

The 28-spotted potato ladybird or Hadda beetle, Epilachna vigintioctopunctata Fab. (syn. Henosepilachna vigintioctopunctata Fab.) (Coleoptera: Coccinellidae), is one of the devastating pests of vegetable crops in Bangladesh (Alam 1969). It is fairy common throughout the country and causes considerable damage to a number of solanaceous, cucurbitaceous and leguminous crops (Anam et al. 2006; Rahaman et al. 2008). Using various plant extracts, attempts have been made to save such crops as potato (Rajagopal and Trivedi 1989), brinjal (Sreedevi et al. 1993; Ghatak and Mondal 2008), oilseed (Ahmed 2007; Ahmed et al. 2010), cucumber (Mondal and Ghatak 2007; 2009) and bitter gourd (Rahaman et al. 2008) against the attacks of the beetle.

Various plant parts possess defense chemicals that play roles against insect herbivores (Konno et al. 2006; Ali et al. 2011). Ahmed (2007) reported that aqueous extract sprays of the castor oil plant Ricinus communis L. (F. Euphorbiaceae) reduced Epilachna attack on foliage and capitulum of sunflower Helianthus annulus and consequently increased the oilseed crop. Subsequently, methanol extracts of $R$. communis were found to have larvicidal properties against the mosquitoes Aedes aegypti (Zahir et al. 2009) and Anopheles arabiensis and Culex quinquefasciatus (Elimam et al. 2009a). 
Aqueous extracts of the milkweed Calotropis procera (Aiton) (F. Asclepiadaceae) were shown to have oviposition deterrant, larvicidal and ovicidal activities against mosquito (Singh et al. 2005; Kabir et al. 2011), reduced population build-up in Henosepilachna elaterii (Ahmed et al. 2006) and controlled Anopheles and Culex populations (Elimam et al. 2009b). While leaf extracts of the downy thorn apple Datura metel L. (F. Solanaceae) were found effective against the stored product beetles Callosobruchus chinensis (Rajapakse and Senanayake (1997) and Trogoderma granarium (Dwivedi and Kumar 1999). Keeping the aforesaid strategies in view, effects of crude aqueous extracts of leaves of the above three indigenous plants were assessed on the larvicidal bioassays and some vital lifehistory traits in E. vigintioctopunctata.

\section{Materials and Methods}

Test insects: Adults of E. vigintioctopunctata were collected from the leaves of three available egg-plants viz. Solanum melongena (Begun), S. nigrum (Futi Begun) and S. indicum (Tit Begun). The experimental beetles were identified by the presence of characteristic black spots on their elytra (Dieke, 1947). For stock culturing, techniques described by Ahmed (1983) were adopted. Newly emerged adults were mated singly in separate plastic containers $(5 \mathrm{~cm} \times 7.5 \mathrm{~cm})$ that had fresh middle-aged leaves of the host plants as food. The containers were covered with fine muslin cloth to prevent escaping of the beetles. Third-instar larvae were transferred from the stock cultures into rearing cages $(80 \mathrm{~cm} \times 45 \mathrm{~cm} \times 40 \mathrm{~cm})$ for emergence of the adults.

Test plants and their extracts: Considering the availability, handling convenience and efficacy, three species of indigenous plants viz. C. procera, $R$. communis and $D$. metel were selected for the present experiments. The plants usually grow abundantly in arid and semi-arid regions without irrigation, fertilizer, pesticide, or other agronomic practices. Identities of the plants were confirmed at the Department of Botany, University of Rajshahi, and voucher specimens have been preserved as herbarium sheets for future reference. Fresh and middle-aged leaves were collected from Rajshahi University Campus and around Rajshahi Metropolitan areas, brought to the laboratory, rinsed in tap water, cut into small pieces, and dried in the shade at ambient temperature $\left(35 \pm 1^{\circ} \mathrm{C}\right)$ and uncontrolled relative humidity $(75 \pm 5 \%)$ for about three weeks. The dried specimens were then ground with the help of an electric blender to form fine powder, sieved, sealed in reagent bottles and refrigerated at $4^{\circ} \mathrm{C}$ until extraction was made.
Crude extracts were made in distilled water as follows. For each plant, a stock solution was prepared by taking $10 \mathrm{~g}$ of the leaf dust in a $250 \mathrm{ml}$ conical flask to which $100 \mathrm{ml}$ distilled water was added, soaked, and kept in an electric shaker for 24h. The foliage aqueous extracts thus obtained were filtered, sealed and refrigerated at $4^{\circ} \mathrm{C}$ until used. Initially a pilot experiment was conducted with the plant extracts to select the doses. Finally, the extracts were diluted volumetrically to obtain $10 \%, 20 \%$ and $30 \%$ solutions by pipetting $25 \mathrm{ml}, 50 \mathrm{ml}$ and $75 \mathrm{ml}$ stock solutions, respectively into $250 \mathrm{ml}$ distilled water in separate reagent bottles. For control groups, only distilled water was used.

Treatment protocol: For treatments S. indicum (F. Solanaceae) leaves were drenched into each dose of the extracts for a few minutes, dried at room temperature and placed on a piece of moistened sponge kept at the bottom of the plastic containers. For each dose and plant species, 20 third-instar larvae of $E$. vigintioctopunctata were placed on the treated leaves and the larvicidal effects of each extract were monitored by counting the number of dead larvae at 24h intervals up to three days (72h). Finally, the larvicidal efficacy was determined by the use of the median lethal concentration $\left(\mathrm{LC}_{50}\right)$ for each extract. To study the life-history traits, 10-day oviposition, egg-hatch (\%), larval duration (days), numbers of pupae formed and adults emerged, and female ratio (i.e. number of females $\div$ total number of adults) were recorded. Single pair-matings of newly emerged beetles were made in plastic containers. Each dose was replicated five times and controls were maintained for comparisons.

Statistical procedures: Cumulative larval mortality data recorded up to $72 \mathrm{~h}$ post treatment were loaded on to the GWBASIC Probit Analysis software to determine $\mathrm{LC}_{50}$ values, 95\% fiducial limits (lower and upper) and regression equations. In addition, one-way ANOVA, followed by the least significant difference (LSD) tests using SPSS for Windows (version 11.5) were performed to analyze the significance of the data on life-history traits.

\section{Results and Discussion}

\section{Larvicidal efficacy of the plant extracts}

The $\mathrm{LC}_{50}$ values from $72 \mathrm{hrs}$ dose-mortality data on the third-instar larvae of E. vigintioctopunctata were estimated to be $18.40 \%, 23.70 \%$ and $29.61 \%$ for $R$. communis, C. procera and D. metel, respectively (Table 1 ). Results indicate that $R$. communis was the most toxic whereas $D$. metel was the least toxic against the beetles. Dose-mortality responses of the three extracts are graphically represented in Fig. 1. 
Table 1. Estimated $\mathrm{LC}_{50}$ values, 95\% confidence limits, regression equations and $\chi^{2}$ values for the aqueous extracts of leaves from three plant species against third-instar larvae of E. vigintioctopunctata.

\begin{tabular}{|c|c|c|c|c|c|}
\hline \multirow[b]{2}{*}{ Plant species } & \multirow{2}{*}{$\begin{array}{c}\mathrm{LC}_{50} \\
(\%)\end{array}$} & \multicolumn{2}{|c|}{ 95\% confidence limits } & \multirow{2}{*}{ Regression equations } & \multirow{2}{*}{$\chi^{2}$ values (df) } \\
\hline & & Lower (\%) & Upper (\%) & & \\
\hline R. communis & 18.40 & 13.51 & 25.06 & $Y=2.1894 x+1.9687$ & $2.57(1)$ \\
\hline C. procera & 23.70 & 16.36 & 34.34 & $Y=2.4417 x+1.9316$ & $9.66(1)$ \\
\hline D. metel & 29.61 & 17.15 & 51.15 & $Y=2.4207 x+1.5584$ & $0.69(1)$ \\
\hline
\end{tabular}
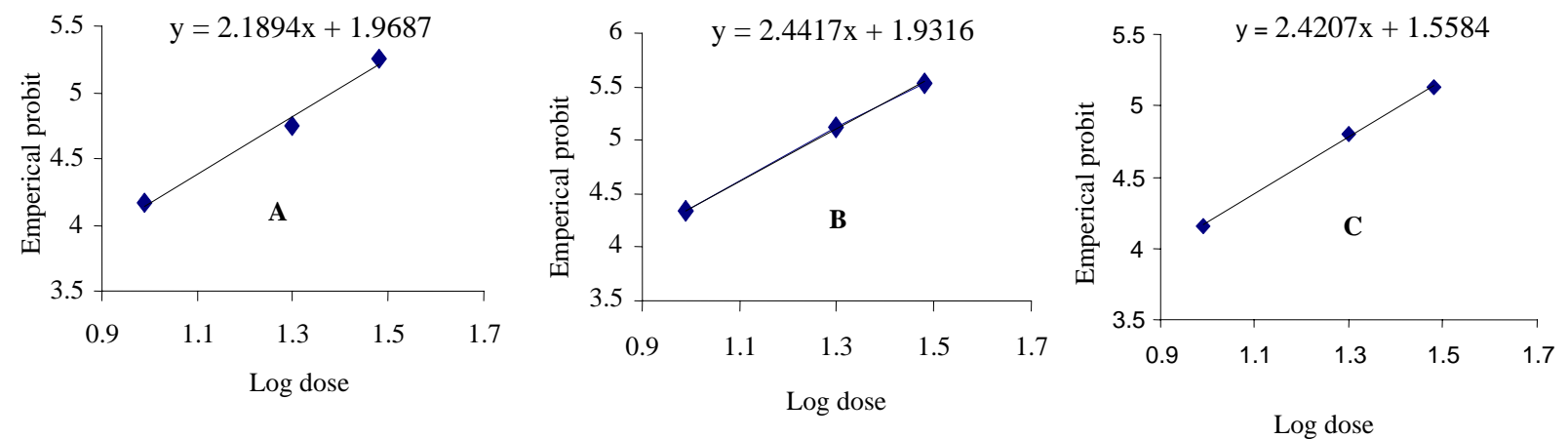

Fig. 1. Probit regression lines for the aqueous extracts of leaves of $R$. communis (A), C. procera (B) and D. metel (C) on the third-instar larvae of E. vigintioctopunctata.

Table 2. Efficacy of the aqueous extracts of leaves derived from three plant species against some life-history traits in $E$. vigintioctopunctata.

\begin{tabular}{|c|c|c|c|c|}
\hline $\begin{array}{c}\text { Plant species } \\
\left(\mathrm{LC}_{50}\right)^{1}\end{array}$ & Oviposition* $^{*}$ & $\begin{array}{c}\text { Egg-hatch } \\
(\%)\end{array}$ & $\begin{array}{c}\text { Larval } \\
\text { duration (d) }\end{array}$ & Female ratio** $^{*}$ \\
\hline $\begin{array}{c}\text { Control } \\
(0.00 \%)\end{array}$ & $37.87 \pm 5.46^{\mathrm{a}}$ & $67.59 \pm 2.47^{\mathrm{a}}$ & $13.20 \pm 0.17^{\mathrm{a}}$ & $0.50 \pm 0.05^{\mathrm{a}}$ \\
\hline $\begin{array}{c}\text { R. communis } \\
(18.40 \%)\end{array}$ & $25.67 \pm 5.52^{\mathrm{b}}$ & $52.27 \pm 11.82^{\mathrm{b}}$ & $15.17 \pm 0.80^{\mathrm{b}}$ & $0.44 \pm 0.06^{\mathrm{a}}$ \\
\hline $\begin{array}{c}\text { C. procera } \\
(23.70 \%)\end{array}$ & $20.93 \pm 1.86^{\mathrm{c}}$ & $62.10 \pm 9.35^{\mathrm{b}}$ & $13.53 \pm 0.80^{\mathrm{a}}$ & $0.50 \pm 0.04^{\mathrm{a}}$ \\
\hline $\begin{array}{c}\text { D. metel } \\
(29.61 \%)\end{array}$ & $36.20 \pm 5.21^{\mathrm{a}}$ & $65.25 \pm 3.03^{\mathrm{a}}$ & $13.87 \pm 0.47^{\mathrm{a}}$ & $0.45 \pm 0.02^{\mathrm{a}}$ \\
\hline $\begin{array}{c}\text { F-ratios } \\
(\mathrm{df}=2,57)\end{array}$ & $11.72^{* * *}$ & $5.99^{* * *}$ & $9.57^{* * *}$ & $0.88 \mathrm{~ns}$ \\
\hline
\end{tabular}

${ }^{1}$ Estimates are shown in Fig. 1; *10-day egg-layings; All values are mean \pm SD of 5 replicates; Dissimilar superscripts indicate significant difference by LSD tests at $\mathrm{P}<0.05$; $\mathrm{df}=$ degrees of freedom; $* * *=\mathrm{P}<0.001$; ns $=$ not significant.

\section{Effects of leaf extracts on life-history traits}

(a) Oviposition: The oviposition of E. vigintioctopunctata females reared on the host leaves treated with the plant extracts reduced significantly $\left(F_{2}, 57\right.$ $=11.72 ; \mathrm{P}<0.001)$ compared to the control females (Table 2). The highest reduction in egg-laying was recorded for $C$. procera in a dose-dependent manner.

(b) Egg-hatch: The hatchability of eggs laid on treated host leaves reduced significantly from about $68 \%$ in the control to $52 \%, 62 \%$ and $65 \%$ in the treated lines $\left(\mathrm{F}_{2}, 57\right.$
=5.99; $\mathrm{P}<0.001)$, indicating a dose-dependent inhibition in egg-hatching in E. vigintioctopunctata. Similar to oviposition deterrent, the most potent extract inhibiting egg-hatch was of $R$. communis. Relatively poor inhibition was recorded for $D$. metel and C. procera.

(c) Larval duration: The overall larval duration was significantly prolonged in the treated lines $\left(F_{2},{ }_{57}=9.57\right.$; $\mathrm{P}<0.001$ ), where $R$. communis also had the maximum effect. However, differences among the control and other two treatments were not statistically significant. 
(d) Pupae formation: The formation of pupae in E. vigintioctopunctata was significantly inhibited by the leaf extracts $\left(\mathrm{F}_{2},{ }_{57}=4.42 ; \mathrm{P}<0.05\right.$; Fig. 2$)$, where $R$. communis and $C$. procera showed much more drastic effects than that of $D$. metel.

(e) Adult emergence: Significantly fewer adults emerged from the treated lines in comparison with the control $\left(F_{2}, 57=4.87 ; \mathrm{P}<0.05\right.$; Fig. 2$)$. As in pupae formation, $R$. communis and $C$. procera had more pronounced inhibition effects on adult emergence in $E$. vigintioctopunctata.

(f) Female ratio: Unlike the all above life-history traits, female ratio in the treated lines did not differ significantly from the control (Table 2). From the present investigation it was obvious that there was no significant effect of leaf extracts on the female ratio of the beetles. All treated and control lines showed a more or less similar trend.

The present results clearly demonstrate that the foliage extracts of the three indigenous plant species possess remarkable larvicidal properties against $E$. vigintioctopunctata at around $18-30 \%$ concentrations. In addition, the extracts were found to have oviposition deterrent as well as egg-hatch inhibition potentials, which culminated in lengthened larval duration followed by significantly reduced pupae formation and adult emergence. Apparently, these achievements could be attributed to the chemical components like terpenoids and tocopherol present in R. communis (Okonkwo and Okoye 1992), tropane alkaloids in D. metel (Rajapakse and Senanayake 1997) and steroid cardiac aglycones in C. procera (Amin et al. 2000).

A number of studies have been conducted in the past to establish the effectiveness of these plant extracts against various coleopteran pest insects. $R$. communis extracts, for example, were found to suppress the pulse beetles $C$. maculatus (Okonkwo and Okoye 1992) and C. chinensis (Bhargava and Meena 2000; Upasani et al. 2003). Likewise, Amin et al. (2000) and Mollah (2004) experimented with $C$. procera extracts against the lesser grain borer Rhyzopertha dominica and C. maculatus; while extracts of $D$. metel were reported to have reduced the population growth and development of the flour beetle T. cataneum (Khalequzzaman and Islam 1992), C. chinensis (Rajapakse and Senanayake 1997), the Khapra beetle Trogoderma granarium (Dwivedi and Kumar 1999) and R. dominica (Mahal 2002).

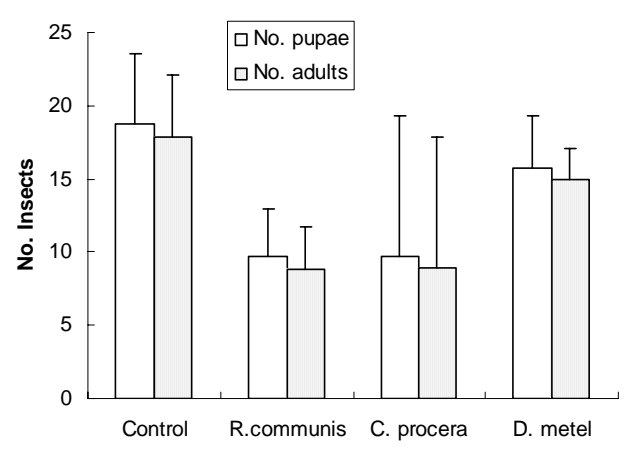

Fig. 2. Effects of aqueous extracts of leaves from three indigenous plants on the number of pupae formed and adults emerged in E. vigintioctopunctata.

Over the last couple of decades, efforts directed at controlling Epilachna beetles infesting various cash crops showed promising results. Rajagopal and Trivedi (1989) observed the repellent and antifeedant properties of neem, mahua and groundnut cakes against $E$. vigintioctopunctata attacking potato whereas Sreedevi et al. (1993) and Mehta et al. (1995) reported success of some plant extracts against $H$. vigintioctopunctata infesting brinjal. The aqueous extracts of the leaf, flower and root of $C$. procera against $H$. elaterii on cucurbit leaves proved much effective because 5\% extract resulted in $100 \%$ protection where no larvae of the pest survived and $1 \%$ and $2.5 \%$ extracts highly reduced fecundity and longevity (Ahmed et al. 2006). Anam et al. (2006) reported that neem oil treatments prolonged larval and pupal periods in E. dodecastigma, in which some treated larvae never pupated; pupal recovery and adult emergence were greatly reduced and the botanical acted as a food deterrent. These findings corroborate the present results in that the extracts were found to have larvicidal, oviposition deterrent and pupal and adulticidal effects against $E$. vigintioctopunctata.

Ten percent aqueous extract spray of $R$. communis leaves was reported to reduce Epilachna attack on foliage and capitulum of sunflower, consequently increasing the yield of oilseed crop (Ahmed 2007) and aqueous seed extracts of Annona squamosa $(5 \mathrm{ml} / \mathrm{L})$, Azadirachtin indica $(6 \mathrm{ml} / \mathrm{L})$ and petroleum ether extract of Acorus calamus ( $2 \mathrm{ml} / \mathrm{L}$ ) reduced population build-up of $H$. vigintioctopunctata infesting cucumber up to $53.24 \%, 41.67 \%$ and $33.16 \%$, respectively (Mondal and Ghatak 2007), while 10\% turmeric and neem seed kernel dusts were found most effective against Epilachna on brinjal (Sankari and Narayanasamy 2007). Moreover, using extracts of indigenous plants Ghatak and Mondal (2008) and 
Mondal and Ghatak (2009) demonstrated excellent suppression of $H$. vigintioctopunctata attacking brinjal and cucumber, respectively. Tephrosia leaf extracts (20g/100 ml water) were shown to kill adults and inhibit pupae formation by Epilachna on bitter gourd (Rahaman et al. 2008), whereas yield of sunflower crop was increased significantly by spraying $5 \% \quad R$. communis extracts against E. varivestis (Ahmed et al. 2010). Recently, Swaminathan et al. (2010) have demonstrated the antifeedant and lethal effects of $A$. indica, Pongamia glabra and Madhuca latifolia on $\mathrm{H}$. vigintioctopunctata. The above results are very similar to the present ones owing to the fact that the present extracts were capable of inducing higher larval moratily, inhibited both egg-laying and egg-hatching, increased immature developmental period, and reduced the number of pupae and adults in the experimental $E$. vigintioctopunctata under laboratory conditions.

The present data suggest that the shaker aqueous extracts of the three indigenous plants could be potent agents against Epilachna beetles. The prime merit of such botanical insecticides is that these could easily and cheaply be prepared by the farmers and/or manufactured by small-scale industries as crude or partially purified forms. However, future comprehensive investigations at field levels are needed to ascertain the eco-friendly nature of the extracts under study.

\section{Conclusion}

Larvicidal bioassays with crude aqueous leaf extracts of three plants viz. R. communis, C. procera and D. metel from Rajshahi University Campus showed significant toxicity against the experimental Epilachna beetles. Vital life-history traits like egg-laying, hatchability, larval duration, pupae formation and adult emergence were also adversely affected by the extract treatments.

Acknowledgements: This forms part of $\mathrm{PhD}$ work by $\mathrm{KI}$, who would like to extend his gratefulness to the Chairmen, Departments of Zoology and Genetic Engineering \& Biotechnology, University of Rajshahi, Bangladesh for providing laboratory facilities. He is also indebted to Shahjalal University of Science and Technology, Sylhet, for granting him study leave, and to the University Grants Commission (UGC) of Bangladesh for providing him financial support. Technical assistance provided by Mr. Md. Nazmul Haque, Laboratory Attendant, is also thankfully acknowledged.

\section{References}

Ahmed A 1983. Bionomics, ecology and control of Epilachna beetles of Rajshahi University Campus and adjacent areas. Unpubl. MPhil thesis, Dept. of Zoology, RU. 124 pp.

Ahmed KN 2007. Effect of biopesticides in the suppression of major insect pests and yield of oilseed crops under different climatic conditions in Bangladesh. Proc. Natl. Symp. Plant Protection-Technology Interface, December 28-29, 2007; pp. 81-82. Assoc. Adv. Plant Protection, Bidhan Chandra Krishi Viswavidyalaya, Nadia, West Bengal, India.

Ahmed KN, Pramanik SHA, Khatun M., Nargis A and Hasan MR 2010. Efficacy of plant extracts in the suppression of insect pests and their effect on the yield of sunflower crop under different climatic conditions. $J$. Plant Prot. Sci. 2(1): 53-58.

Ahmed UAM, Zuhua S, Bashier NH H, Muafi K, Zhongping $\mathrm{H}$ and Yuling $\mathrm{G}$ 2006. Evaluation of insecticidal potentialities of aqueous extracts from Calotropis procera Ait. against Henosepilachna elaterii Rosii. J. Appl. Sci. 6(11): 2466-2470.

Alam MZ 1969. Insect Pests of Vegetables and Their Control in East Pakistan. Agric. Inf. Service, Dept. of Agriculture, RK Mission Rd, Dacca. 146 pp.

Ali H, Ahmed S, Hassan G, Amin A and Naeem M 2011. Efficacy of different botanicals against red pumpkin beetle (Aulacophora foveicollis) in bitter gourd (Mormordica charantia L.). Pak. J. Weed Sci. Res. 17(1): 65-71.

Amin MR, Shahjahan M, El-Taj HF, Iqbal TMT and Hussain MA 2000. Use of akanda, biskatali, and neem leaves as botanical insecticides against lesser grain borer. Bangladesh J. Entomol. 10(1\&2): 1-13.

Anam M, Ahmad M. and Haque MA 2006. Efficacy of neem oil on the biology and food consumption of epilachna beetle, Epilachna dodecastigma (Weid.). J. Agric. Rural Dev. 4(1\&2): 83-88.

Bhaduri M, Gupta DP and Ram S 1989. Effect of vegetable oils on the ovipositional behaviour of Callosobruchus maculatus (Fab.). Proc. $2^{\text {nd }}$ Int. Symp. On Bruchids and Legumes (ISLB-2) held at Okayama, Japan; 6-9 September 1989. pp. 81-84.

Bhargava MC and Meena HM 2000. Efficacy of some vegetable oils against pulse beetle, Callosobruchus chinensis (Linn) on cowpea [Vigna unguiculata (L.)] Entomocongress, 5-8 November, Trivandrum, Kerala, India $49 \mathrm{pp}$.

Devi DA, Mohandas N and Vistakshy A 1986. Residues of Fenthion, Quinphos and Malathion in paddy grains following surface treatment of gunny bags. Agric. Res. J. Kerala 24(2): 222-224.

Dieke GH 1947. Ladybeetles of the genus Epilachna (sens. lat.) in Asia, Europe and Australia. Smithson. Misc. Collect. 106(15): 183 pp.

Dwivedi SC and Kumar RR 1999. Screening of some plant extracts for their oviposition deterrent properties against the Khapra beetle, Trogoderma granariun E. $J$. Adv. Zool. 20(1): 6-9.

Elimam AM, Elmalik KH and Ali FS 2009a. Larvicidal, adult emergence inhibition and oviposition deterrent effects of foliage extract from Ricinus communis L. against Anopheles arabiensis and Culex quinquefasciatus in Sudan. Trop Biomed. 26(2):130-139. 
Elimam AM, Elmalik KH and Ali FS 2009b. Efficacy of leaves extract of Calotropis procera Ait. (Asclepiadaceae) in controlling Anopheles arabiensis and Culex quinquefasciatus mosquitoes. Saudi J. Biol. Sci. 16: 95-100.

Fishwick RB 1988. Pesticide residues in grain arising from post harvest treatments. Aspects Appl. Biol. 17(2): 37-46.

Ghani A 1998. Medicinal Plants of Bangladesh: Chemical Constituents and Uses. Asiatic Society of Bangladesh, Dhaka. 238 pp.

Ghatak SS and Mondal S 2008. Feasibility of using plant products and biopesticides against epilachna beetle, Henosepilachna vigintioctopunctata Fabr. infecting brinjal. Indian J. Entomol. 70(3): 278-279.

Hagen KS and Franz JM 1973. A history of biological control. In: History of Entomology (eds. Smith RF, Mittler TE and Smith CN) pp. 433-467. Annual Rev. Inc., California. 872 pp.

Kabir KE, Khan AR and Rahman ASMS 2011. Larvicidal effect of latex from Calotropis gigantea (L.) W.T. Aiton against the mosquito, Culex quinquefasciatus Say (Diptera: Culicidae). Univ. j. zool. Rajshahi Univ. 29: 77-80.

Khalequzzaman $\mathrm{M}$ and Islam MN1992. Pesticidal action of Dhatura, Datura metel Linn., leaf extracts on Tribolium castaneum (Herbst). Bangladesh J. Zool. 20(2): 223-229.

Konno K, Ono H, Nakamura M, Tateishi K, Hirayama C, Tamura Y, Hattori M, Koyama A and Kohno K 2006. Mulberry latex rich in antidiabetic sugar-mimic alkaloids forces dieting on caterpillars. Proc. Natl. Acad. Sci. USA 103: 1337-1341.

Mahal N 2002. Biology and control of Rhyzopertha dominica (Fabricius) (Coleoptera: Bostrichidae). Unpubl. PhD thesis, Institute of Biological Sciences, RU. 270+59 pp.

Mehta PK, Vaidya DN and Kashyap NP 1995. Antifeedant properties of some plant extracts against brinjal hadda beetle, Henosepilachna vigintioctopunctata Fab. J. Entomol. Res. 19(2): 147-150.

Mollah MJU 2004. Efficacy of some indigenous plant products against Callosobruchus maculatus F. Unpubl. PhD thesis, Institute of Biological Sciences, RU. 176+31 pp.

Mondal S and Ghatak SS 2007. Bioefficacy of some indigenous plant extracts against epilachna beetle [Henosepilachna vigintioctopunctata, Fabr.] infesting cucumber. Proc. Natl. Sym. Plant ProtectionTechnology Interface, December 28-29, 2007; p. 107. Assoc. Adv. Plant Protection, Bidhan Chandra Krishi Viswavidyalaya, Nadia, West Bengal, India.

Mondal S and Ghatak SS 2009. Bioefficacy of some indigenous plant extracts against epilachna beetle (Henosepilachna vigintioctopunctata Fabr.) infesting cucumber. J. Plant Prot. Sci. 1(1): 71-75.
Okonkwo EU and Okoye WI 1992. The control of Callosobruchus maculatus (F.) in stored cowpea with dried ground Ricinus communis L. leaves in Nigeria. Trop. Pest Manag. 38(3): 237-238.

Rahaman MA, Prodhan MDH and Maula AKM 2008. Effect of botanical and synthetic pesticides in controlling Epilachna beetle and the yield of bitter gourd. Int. J. Sustain. Crop Prod. 3(5): 23-26.

Rajagopal D and Trivedi TP 1989. Status, bioecology and management of Epilachna beetle, Epilachna vigintioctopunctata (Fab.) (Coleoptera: Coccinellidae) on potato in India: A review. Trop. Pest Management 35(4): 410-413.

Rajapakse RHS and Senanayake SGJN 1997. Effectiveness of seven vegetable oils against Callosobruchus chinensis L. in pigeon pea Cajanus cajan L. Entomol. 22(3\&4): 179-183.

Sankari SA and Narayanasamy P 2007. Bio-efficacy of flyashbased herbal pesticides against pests of rice and vegetables. Current Sci. 92(6): 811-816.

Saxena RC, Epino PB, Cheng-Wne TU and Puma BC 1983. Neem, chinaberry and custard apple: Antifeedant and insecticidal effects of seed oils on leaf hoppers and plant hopper pests of rice. Proc. $2^{\text {nd }}$ Int. Neem Conf. held on 2528 May 1983. Rauisch-Holshausen, FRG. pp. 391-402.

Singh RK, Mittal PK and Dhiman RC 2005. Laboratory study on larvicidal properties of leaf extract of Calotropis procera (Family Asclepiadaceae) against mosquito larvae. J. Commun. Dis. 37(2): 109-113.

Sreedevi, K, Chitra, KC \& Rao, K. 1993. Effect of certain plant extracts against brinjal leaf beetle, Henosepilachna vigintioctopunctata Fab. under greenhouse conditions. Indian J. Entomol. 55(3): 329-331.

Swaminathan R, Manjoo S and Hussain T 2010. Anti-feedant activity of some biopesticides on Henosepilachna vigintioctopunctata (Fab.) (Coleoptera: Coccinellidae). J. Biopesticides 3(1): 77-80.

Upasani SM, Kotkar HM, Mendki PS and Maheshwari VL 2003. Partial characterization and insecticidal properties of Ricinus communis L. foliage flavonoids. Pest Manag. Sci. 59(12): 1349-1354.

Zahir AA, Rahuman AA, Kamaraj C, Bagavan A, Elango G, Sanganan A and Kumar B 2009. Laboratory determination of efficacy of indigenous plant extracts for parasites control. Parasitol. Res. 105: 453-461.

Manuscript revised on 24 November 2011 and accepted on 24 December 2011 